11

\title{
Квантовый выход люминесценции и константы рекомбинации в коллоидных core/shell квантовых точках $\mathrm{Ag}_{2} \mathrm{~S} / \mathrm{ZnS}$ и $\mathrm{Ag}_{2} \mathrm{~S} / \mathrm{SiO}_{2}$
}

\author{
(C) О.В. Овчинников, М.С Смирнов ", С.В. Асланов \\ Воронежский государственный университет, \\ 394006 Воронеж, Россия \\ ฯ e-mail: smirnov_m_s@mail.ru \\ Поступила в редакцию 27.07.2020 г. \\ В окончательной редакции 27.07.2020 г. \\ Принята к публикации 01.09.2020 г.
}

\begin{abstract}
Выполнен сравнительный анализ люминесцентных свойств коллоидных квантовых точек $\operatorname{Ag}_{2} \mathrm{~S}$, покрытых тиогликолевой кислотой или 2-меркаптопропионовой кислотой с оболочками из $\mathrm{ZnS}$ или $\mathrm{SiO}_{2}$. Продемонстрировано увеличение квантового выхода рекомбинационной ИК люминесценции коллоидных квантовых точек $\mathrm{Ag}_{2} \mathrm{~S}$ до 35 раз в результате формирования оболочек $\mathrm{ZnS}, \mathrm{SiO}_{2}$ при одновременном увеличении среднего времени жизни люминесценции. Для квантовых точек ядро/оболочка $\mathrm{Ag}_{2} \mathrm{~S} / \mathrm{ZnS}$, покрытых тиогликолевой кислотой, показано уменьшение излучательной и безызлучательной констант рекомбинации, которое объяснено локализацией электронов в оболочке, а дырок в ядре. Для квантовых точек ядро/оболочка $\mathrm{Ag}_{2} \mathrm{~S} / \mathrm{SiO}_{2}$ покрытых 2-меркаптопропионовой кислотой наблюдалось увеличение констант излучательной и уменьшение безызлучательной рекомбинации. В этом случае рост константы излучательной рекомбинации обусловлен локализацией электронов и дырок в ядре. Уменьшение константы безызлучательной рекомбинации объяснено пассивацией интерфейсных дефектов квантовых точек при формировании оболочки.
\end{abstract}

Ключевые слова: квантовые точки, люминесценция, константы рекомбинации, core/shell.

DOI: $10.21883 /$ OS.2020.12.50331.206-20

\section{1. Введение}

Разработка приемов управления квантовым выходом люминесценции полупроводниковых квантовых точек (КТ) крайне интересна для решения широкого спектра технических задач в области квантовой сенсорики, биомедицинских технологий, инженерии и оптоэлектроники [1-6]. Управление характеристиками размернозависимой ИК люминесценции КТ $\mathrm{Ag}_{2} \mathrm{~S}$ практически важно в силу их низких водорастворимости и токсичности [7-11]. Существенная нестехиометрия сульфида серебра и его фотохимическая активность оказывают нежелательное воздействие на квантовый выход (QY) люминесценции, и даже приводят к заметной деградации его люминесцентных свойств под действием возбуждающего излучения [12-19]. Поскольку рекомбинационная люминесценция KT $\mathrm{Ag}_{2} \mathrm{~S}$ имеет интерфейсную природу [20,21], формирование структур ядро/оболочка на их основе является эффективным способом повышения QY. Известны попытки формирования различных структур ядро/оболочка, таких как $\mathrm{Ag}_{2} \mathrm{~S} / \mathrm{ZnS}$ [2527], $\mathrm{Ag}_{2} \mathrm{~S} / \mathrm{CdS}$ [28], $\mathrm{Ag}_{2} \mathrm{~S} / \mathrm{SiO}_{2}$ [11], $\mathrm{Ag}_{2} \mathrm{~S} / \mathrm{Ag}_{2} \mathrm{WO}_{4}$ [29], $\mathrm{Ag} 2 \mathrm{~S} / \mathrm{SnS} 2$ [30]. Отмечается, что формирование оболочки приводит к росту QY люминесценции. Однако глубокое рассмотрение фотофизических процессов в КТ, обеспечивающих их люминесцентные свойства, а также анализ влияния на люминесцентные параметры формирующихся оболочек отсутствует. Предполагается также, что на люминесцентные свойства КТ влияет тип оболочки. В этом случае решающую роль играет соотношение взаимного расположения энергетических состояний ядра и оболочки. Теоретически эта проблема рассмотрена в работах [31-33]. Однако для КТ $\mathrm{Ag}_{2} \mathrm{~S}$ такое рассмотрение отсутствует. Таким образом, фундаментальная проблема управления параметрами люминесценции КТ на стадии синтеза остаётся нерешенной.

Данная работа частично восполняет этот пробел. Основной целью работы был сравнительный анализ ИК люминесцентных свойств покрытых тиогликолевой кислотой (TGA) и 2-меркаптопропионовой кислотой (2-MРА) систем ядро/оболочка $\mathrm{Ag}_{2} \mathrm{~S} / \mathrm{ZnS}$ и $\mathrm{Ag}_{2} \mathrm{~S} / \mathrm{SiO}_{2}$.

\section{2. Исследуемые образцы}

Использованные реактивы: нитрат серебра $\left(\mathrm{AgNO}_{3}\right)$, 2-меркаптопропионовая кислота (2-MРA), тиогликолевая кислота (TGA), ацетат цинка $\mathrm{Zn}\left(\mathrm{CH}_{3} \mathrm{COOH}\right)_{2}$, этиленгликоль, метасиликат натрия $\left(\mathrm{Na}_{2} \mathrm{SiO}_{3}\right)$, 3-меркаптопропилтриметоксисилан (MPTMS), тетраэтоксисилан (TEOS) фирмы Sigma-Aldrich.

Коллоидные КT $\mathrm{Ag}_{2} \mathrm{~S} / \mathrm{TGA}$ синтезировали в воде с использованием $\mathrm{Na}_{2} \mathrm{~S}$ в качестве источника серы [20]. Молекулы TGA использовались в качестве органического лиганда. Для формирования структур ядро/оболочка $\mathrm{Ag} 2 \mathrm{~S} / \mathrm{ZnS}$ при температуре $45^{\circ} \mathrm{C}$ в раствор коллоидных КТ добавлялся водный раствор ацетата цинка до достижения соотношения $\left[\mathrm{Ag}_{2} \mathrm{~S}\right]:[\mathrm{Zn}]$, равного $1: 1$, с последующим выдерживанием в течение $5 \mathrm{~min}$ при 
температуре $45^{\circ} \mathrm{C}$. При большей концентрации прекурсора цинка наблюдалось выпадение серого осадка. Формирование структур ядро/оболочка $\mathrm{Ag}_{2} \mathrm{~S} / \mathrm{SiO}_{2}$ осуществляли в два этапа. На первом в раствор КТ вносился предварительно гидролизованный в этаноле 3меркаптопропилтриметоксисилан (MPTMS) - прекурcop $\mathrm{SiO}_{2}$ - в соотношении $\left[\mathrm{Ag}_{2} \mathrm{~S}\right]:[\mathrm{MPTMS}]$, равном $1: 1$. Это обеспечивало формирование субмонослойного покрытия. На втором этапе производили увеличение толщины оболочки внесением водного раствора метасиликата натрия $\left(\mathrm{Na}_{2} \mathrm{SiO}_{3}\right)$ в соотношении $\left[\mathrm{Ag}_{2} \mathrm{~S}\right]:\left[\mathrm{Na}_{2} \mathrm{SiO}_{3}\right]$, равном $1: 3$.

Коллоидные КT $\mathrm{Ag}_{2} \mathrm{~S} / 2$-MPA получены при помощи методики фотоиндуцированного синтеза в этиленгликоле [34]. Молекулы 2-МРА выступали как органический лиганд и источник серы. Синтез $\mathrm{Ag}_{2} \mathrm{~S} / \mathrm{ZnS}$ на основе KT $\mathrm{Ag}_{2} \mathrm{~S} / 2-\mathrm{MPA}$ происходил путём внесения раствора ацетата цинка в этиленгликоле до соотношения $\left[\mathrm{Ag}_{2} \mathrm{~S}\right]:\left[\mathrm{Zn}\left(\mathrm{CH}_{3} \mathrm{COO}\right)_{2}\right]$, равного $1: 1$, с последующим выдерживанием смеси при $45^{\circ} \mathrm{C}$ в течение $5 \mathrm{~h}$ в темноте. Формирование $\mathrm{Ag}_{2} \mathrm{~S} / \mathrm{SiO}_{2}$ производилось в два этапа. На первом этапе в раствор КТ вносили предварительно гидролизованный MPTMS в соотношении $\left[\mathrm{Ag}_{2} \mathrm{~S}\right]:\left[\mathrm{SiO}_{2}\right]$, равном $10: 1$, после чего смесь перемешивалась в темноте в течение суток. На втором этапе увеличивали толщину оболочки при добавлении этанольного раствора TEOS в соотношении $\left[\mathrm{Ag}_{2} \mathrm{~S}\right]:\left[\mathrm{SiO}_{2}\right]$, равном $1: 3$, смесь ещё в течение суток выдерживалась в темноте.

\section{3. Методики экспериментальных исследований}

Структурные исследования КТ выполняли с помощью просвечивающего электронного микроскопа (TEM) Libra 120 PLUS с ускоряющим напряжением $120 \mathrm{kV}$ (Carl Zeiss, Германия). Распределения по размерам получали при анализе ТЕМ-изображений.

Исследование спектров оптического поглощения осуществляли с использованием спектрометра USB2000+ с источником излучения USB-DT (Ocean Optics, США). Для исследования спектров фотолюминесценции в области 400-1000 nm использовался спектрометр USB2000+, а в области 800-1200 nm - дифракционный монохроматор МДР-4 (ЛОМО, Россия) и фотодиод PDF10C/M (ThorLabs Inc. CША). Источником возбуждения был полупроводниковый лазерный диод NDB7675 (Nichia, Япония) с длиной волны $462 \mathrm{~nm}$ и оптической мощностью $0.5 \mathrm{~W}$.

Кривые затухания люминесценции исследовались методом время-коррелированного однофотонного счёта с применением платы TimeHarp 260 (PicoQuant, Германия), модуля ФЭУ РМС-100-20 (Becker \& Hick1, Германия) в области до $900 \mathrm{~nm}$ с временным разрешением $0.2 \mathrm{~ns}$. Для аппроксимации быстрой компоненты кривой затухания люминесценции использовали процедуру деконволюции с экспериментально измеренной функцией отклика аппаратуры. В качестве источника возбуждения использовался УФ импульсный полупроводниковый лазеp Alphalas PLDD-250 (Alphalas, Германия) с длиной волны $375 \mathrm{~nm}$, длительностью импульсов 60 рs и частотой повторения импульсов $100 \mathrm{kHz}$.

Измерение QY люминесценции образцов производили методом сравнения с эталоном. Эталоном служил раствор красителя индоцианина зеленого (ICG) в диметилсульфоксиде (DMSO) с QY 13\% [35]. Вычисление интегральной интенсивности полос люминесценции осуществляли с учётом спектральной чувствительности фотоприёмника, определённой с использованием эталонной ленточной вольфрамовой лампы с известной цветовой температурой. QY люминесценции образца вычислялся при помощи выражения [36]

$$
Q Y_{\text {sample }}=Q Y_{\text {ref }} \frac{I_{\text {sample }}}{I_{\text {ref }}} \frac{O D_{\text {ref }}}{O D_{\text {sample }}} \frac{n_{\text {sample }}^{2}}{n_{\text {ref }}^{2}},
$$

где $Q Y_{\text {ref }}$ - квантовый выход эталона, $I_{\text {sample }}$ и $I_{\text {ref }}-$ интегральные интенсивности люминесценции образца и эталона соответственно, $O D_{\text {sample }}$ и $O D_{\text {ref }}$ - оптические плотности образца и эталона соответственно, $n_{\text {sample }}$ и $n_{\text {ref }}$ - показатели преломления образца и эталона соответственно.

\section{4. Результаты и их обсуждение}

\section{1. Структурные свойства ансамблей коллоидных KT $\mathrm{Ag}_{2} \mathrm{~S} / \mathrm{TGA}, \mathrm{Ag}_{2} \mathrm{~S} / 2-\mathrm{MPA}$ и ядро/оболочка $\mathrm{Ag}_{2} \mathrm{~S} / \mathrm{SiO}_{2}$ и $\mathrm{Ag}_{2} \mathrm{~S} / \mathrm{ZnS}$}

ТЕМ-изображения и гистограммы распределения ансамблей по размерам приведены на рис. 1.

Синтезированные образцы КT $\mathrm{Ag}_{2} \mathrm{~S} / 2-\mathrm{MPA}$ имели средний размер $2.9 \mathrm{~nm}$ с дисперсией по размеру около $30 \%$. Формирование оболочек $\mathrm{SiO}_{2}$ привело к увеличению среднего размера до $3.3 \mathrm{~nm}$ с дисперсией $35 \%$. При формировании оболочек $\mathrm{ZnS}$ средний размер возрастал до $3.5 \mathrm{~nm}$ при дисперсии 35\%. Образцы КТ $\mathrm{Ag}_{2} \mathrm{~S} / \mathrm{TGA}$ имели средний размер $2.5 \mathrm{~nm}$ с дисперсией около $30 \%$. Формирование оболочек $\mathrm{ZnS}$ привело к увеличению среднего размера до $3.5 \mathrm{~nm}$. Формирование оболочек $\mathrm{SiO}_{2}$ привело к возникновению контрастной фазы толщиной $1.5-4 \mathrm{~nm}$ с образованием редких агломератов из нескольких КТ, покрытых общим слоем $\mathrm{SiO}_{2}$. Средний размер КТ вырос до $4.5 \mathrm{~nm}$.

\section{2. Абсорбционные свойства ансамблей коллоидных KT Ag 2 S/TGA, $\mathrm{Ag}_{2} \mathrm{~S} / 2-\mathrm{MPA}$ и $\mathrm{Ag}_{2} \mathrm{~S} / \mathrm{SiO}_{2}, \mathrm{Ag}_{2} \mathrm{~S} / \mathrm{ZnS}$}

В спектрах поглощения всех образцов, приведенных на рис. 2, a (кривые 1-6) наблюдались характерные для полупроводниковых нанокристаллов широкие спектры поглощения с выраженными особенностями, обусловленными поглощением в основное состояние экситона. Их положение определяли по минимуму второй 

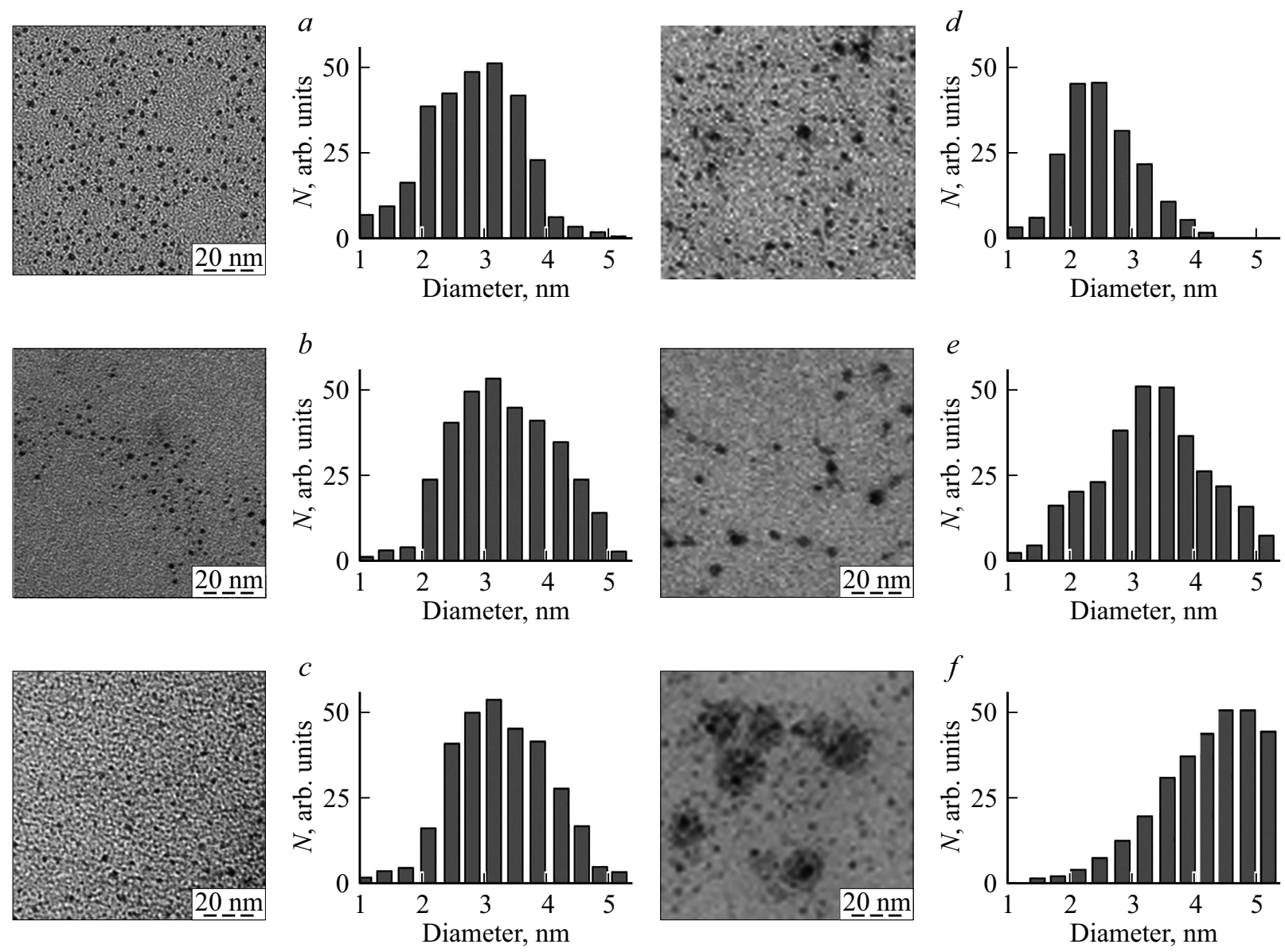

Рис. 1. ТЕМ-изображения и гистограммы распределения по размерам коллоидных квантовых точек $\mathrm{Ag}_{2} \mathrm{~S} / 2-\mathrm{MPA}(a), \mathrm{Ag}_{2} \mathrm{~S} / \mathrm{ZnS} / 2$ MPA (b), $\mathrm{Ag}_{2} \mathrm{~S} / \mathrm{SiO}_{2} / 2-\mathrm{MPA}(c), \mathrm{Ag}_{2} \mathrm{~S} / \mathrm{TGA}(d), \mathrm{Ag}_{2} \mathrm{~S} / \mathrm{ZnS} / \mathrm{TGA}(e), \mathrm{Ag}_{2} \mathrm{~S}_{/} \mathrm{SiO}_{2} / \mathrm{TGA}(f)$.

производной $d^{2} O D / d E^{2}$. Для всех образцов максимум полосы экситонного поглощения был сильно сдвинут в синюю область относительно края поглощения массивного кристалла $\mathrm{Ag}_{2} \mathrm{~S}$ с моноклинной решеткой $\left(E_{g}^{\text {bulk }}=1.0 \mathrm{eV}\right)$ [37]. Наблюдаемое различие вызвано квантовым ограничением в спектрах оптического поглощения КТ.

Величина энергии максимума полосы экситонного поглощения позволяет оценить размер КТ в рамках метода эффективной массы с использованием следующего выражения [38]:

$$
\Delta E=\hbar_{\mathrm{abs}}-E_{g}^{\mathrm{bulk}}=\frac{\hbar^{2} \pi^{2}}{1 \mu R^{2}}-\frac{1.78 e^{2}}{\varepsilon R}-0.248 E_{R y}^{*},
$$

где $E_{g}^{\text {bulk }}=1.0 \mathrm{eV}$ [37] — ширина запрещенной зоны массивного кристалла, $\hbar \omega_{\mathrm{abs}}-$ максимум основного экситонного поглощения, $\mu=\frac{m_{e}^{*} m_{h}^{*}}{m_{e}^{*}+m_{h}^{*}}-$ приведенная масса электрона и дырки, $R-$ радиус КТ, $m_{e}^{*}=0.42 m_{0}$ и $m_{h}^{*}=0.81 m_{0}$ - эффективные массы электрона и дырки соответственно [37], $\varepsilon=5.95$ - диэлектрическая восприимчивость [37], $E_{R y}^{*}$ - энергия пространственной корреляции. Результаты оценки размеров КТ с исполь-
Таблица 1. Энергия экситонного перехода в поглощении, максимума полосы люминесценции, теоретический размер КТ и размер по данным ТЕМ

\begin{tabular}{|c|c|c|c|c|}
\hline $\begin{array}{l}\text { Наименование } \\
\text { образца }\end{array}$ & $\begin{array}{c}\hbar \omega_{\text {abs }}, \\
\mathrm{eV}\end{array}$ & $\begin{array}{c}\hbar \omega_{\text {lum }}, \\
\mathrm{eV}\end{array}$ & $\begin{array}{c}\text { Диаметр КТ } \\
d_{\mathrm{av}}, \mathrm{nm}, \text { расчет }\end{array}$ & $\begin{array}{l}\text { Диаметр КТ } \\
d_{\mathrm{av}}, \mathrm{nm}, \mathrm{TEM}\end{array}$ \\
\hline $\mathrm{Ag}_{2} \mathrm{~S} / 2-\mathrm{MPA}$ & 1.74 & 1.53 & 2.07 & 2.9 \\
\hline $\mathrm{Ag}_{2} \mathrm{~S} / \mathrm{ZnS} / 2-\mathrm{MPA}$ & 1.71 & 1.39 & 2.1 & 3.5 \\
\hline $\mathrm{Ag}_{2} \mathrm{~S} / \mathrm{SiO}_{2} / 2-\mathrm{MPA}$ & 1.71 & 1.51 & 2.1 & 3.3 \\
\hline $\mathrm{Ag}_{2} \mathrm{~S} / \mathrm{TGA}$ & 1.9 & 1.29 & 1.93 & 2.5 \\
\hline $\mathrm{Ag}_{2} \mathrm{~S} / \mathrm{ZnS} / \mathrm{TGA}$ & 1.83 & 1.33 & 1.99 & 3.5 \\
\hline $\mathrm{Ag}_{2} \mathrm{~S} / \mathrm{SiO}_{2} / \mathrm{TGA}$ & 1.63 & 1.31 & 2.19 & 4.5 \\
\hline
\end{tabular}

зованием выражения (2) и по данным ТЕМ приведены в табл. 1.

Видно, что для всех образцов в результате формирования оболочки наблюдается заметное увеличение среднего размера. При этом размеры, оцененные из спектров поглощения и обусловленные размером именно ядра $\mathrm{Ag}_{2} \mathrm{~S}$, изменяются незначительно в пределах 10\%. Это указывает на формирование оболочек. 

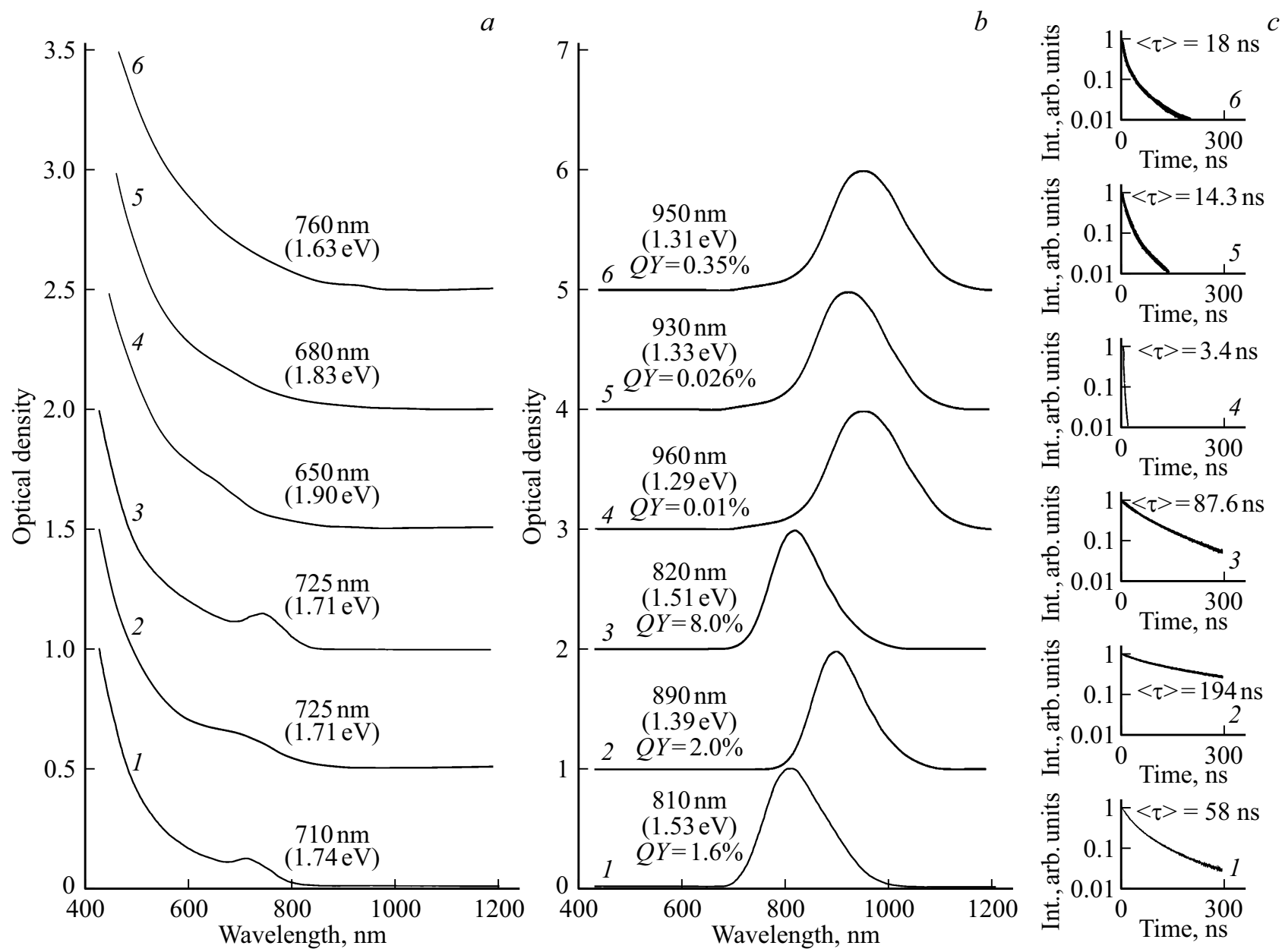

Рис. 2. Спектры поглощения $(a)$, люминесценции $(b)$ и кривые затухания люминесценции (c) изученных образцов КТ $\mathrm{Ag}_{2} \mathrm{~S} / 2$ $\mathrm{MPA}$ - 1, $\mathrm{Ag}_{2} \mathrm{~S} / \mathrm{ZnS} / 2-\mathrm{MPA}$ - 2, $\mathrm{Ag}_{2} \mathrm{~S} / \mathrm{SiO}_{2} / 2-\mathrm{MPA}$ - 3, $\mathrm{Ag}_{2} \mathrm{~S} / \mathrm{TGA}-4, \mathrm{Ag}_{2} \mathrm{~S} / \mathrm{ZnS} / \mathrm{TGA}$ - 5 и $\mathrm{Ag}_{2} \mathrm{~S} / \mathrm{SiO}_{2} / \mathrm{TGA}^{-6}$.

Формирование оболочек $\mathrm{ZnS}$ или $\mathrm{SiO}_{2}$ на КТ $\mathrm{Ag}_{2} \mathrm{~S} / 2$ MPA приводит к длинноволновому сдвигу полосы поглощения экситона на $0.03 \mathrm{eV}$, что является спектральным проявлением формирования оболочки. Это обусловлено частичным проникновением волновой функции носителей заряда в оболочку и уменьшением энергии уровней размерного квантования в КТ. Рассмотрим взаимное расположение энергетических уровней в системе ядро/оболочка, построенных с учётом данных из работ [39-41] (рис. 3).

Как видно из диаграммы, дно зоны проводимости массивного $\mathrm{ZnS}$ расположено немного ниже уровней размерного квантования $\mathrm{Ag}_{2} \mathrm{~S}$, что допускает частичное проникновение электронов в оболочку. Напротив, для оболочки $\mathrm{SiO}_{2}$ этот процесс маловероятен благодаря большой ширине запрещенной зоны массивного $\mathrm{SiO}_{2}$. В таком случае при формировании оболочки $\mathrm{SiO}_{2}$ ожидается синее смещение полосы экситонного поглощения, которого не наблюдается. Наблюдаемое длинноволновое смещение экситонного поглощения в таком случае обусловлено ростом кристаллического ядра $\mathrm{Ag}_{2} \mathrm{~S}$ изза использования серосодержащего прекурсора $\mathrm{SiO}_{2}$
(MPTMS), добавление которого приводит к некоторому увеличению размеров ядра $\mathrm{Ag}_{2} \mathrm{~S}$.

\section{3. Фотолюминесцентные свойства коллоидных KT $\mathrm{Ag}_{2} \mathrm{~S} / \mathrm{TGA}, \mathrm{Ag}_{2} \mathrm{~S} / 2-\mathrm{MPA}$ и KT ядро/оболочка $\mathrm{Ag}_{2} \mathrm{~S} / \mathrm{SiO}_{2}$ и $\mathrm{Ag}_{2} \mathrm{~S} / \mathrm{ZnS}$}

Спектры фотолюминесценции образцов приведены на рис. 2,b (кривые 1-6). Для исследованных образцов KT $\mathrm{Ag}_{2} \mathrm{~S} / 2-\mathrm{MPA}$ наблюдалась ИК люминесценция с максимумом при $810 \mathrm{~nm}$, полушириной полосы около $150 \mathrm{~nm}$ и стоксовым сдвигом относительно максимума полосы экситонного поглощения, составляющим $0.21 \mathrm{eV}$ (рис. 2, $b$, кривая 1), что свидетельствует о рекомбинационном характере люминесценции. QY люминесценции составил $1.6 \%$. Формирование оболочки $\mathrm{ZnS}$ (рис. 2, b, кривая 2) привело к длинноволновому сдвигу максимума люминесценции на $80 \mathrm{~nm}$ без изменения полуширины полосы. При этом увеличился стоксов сдвиг до $0.32 \mathrm{eV}$, что обусловлено захватом электронов оболочкой с последующей их излучательной рекомбинацией посредством пространственно-непрямых переходов [31]. Также отмечается рост QY в 1.25 раза, 

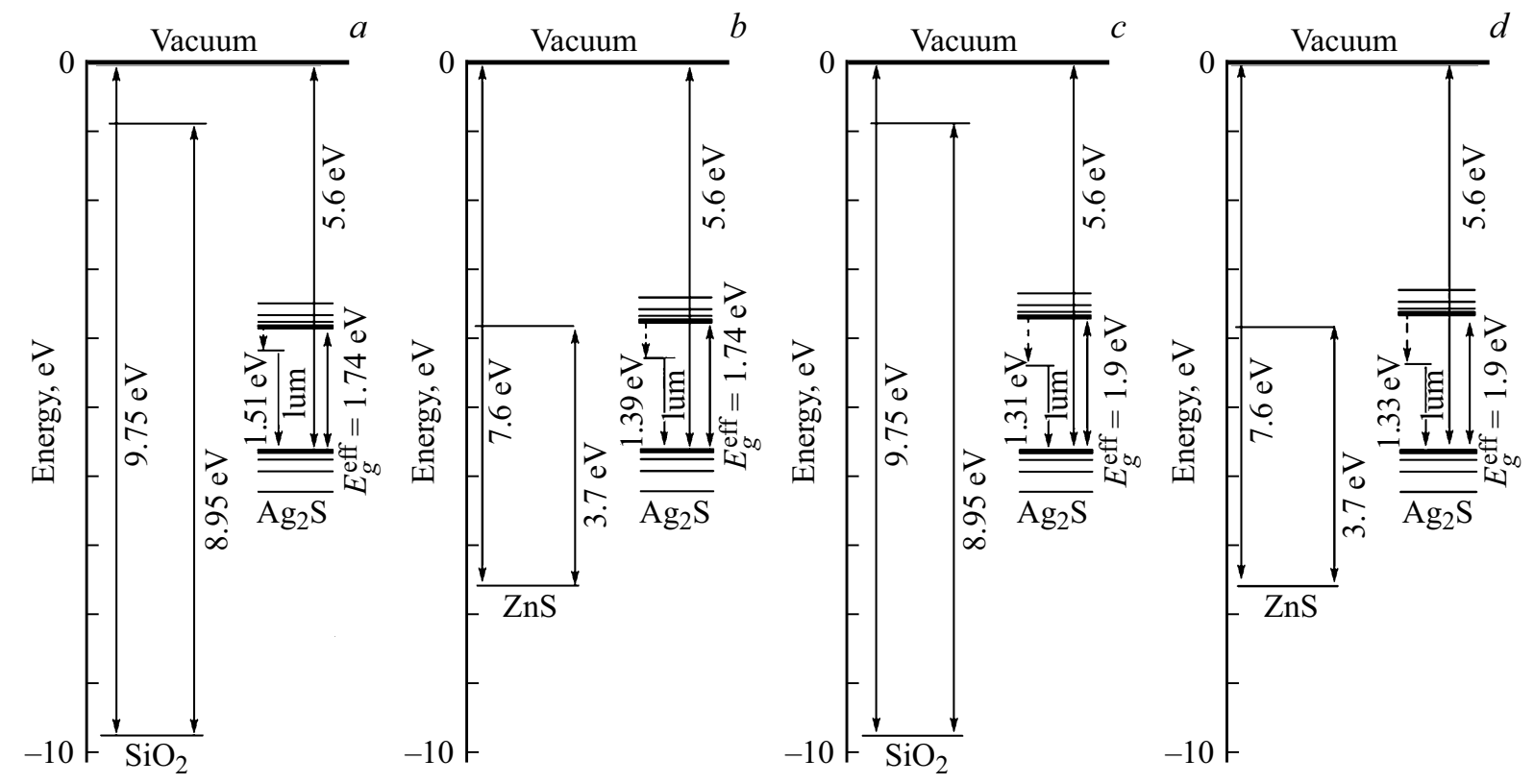

Рис. 3. Энергетическая диаграмма коллоидных КТ ядро/оболочка $\mathrm{Ag}_{2} \mathrm{~S} / \mathrm{SiO}_{2} / 2-\mathrm{MPA}(a), \mathrm{Ag}_{2} \mathrm{~S} / \mathrm{ZnS} / 2-\mathrm{MPA}(b), \mathrm{Ag}_{2} \mathrm{~S} / \mathrm{SiO}_{2} / \mathrm{TGA}(c)$ и $\mathrm{Ag}_{2} \mathrm{~S} / \mathrm{ZnS} / \mathrm{TGA}(d)$.

вызванный пассивацией поверхностных центров безызлучательной рекомбинации при образовании оболочки $[20,42]$. Для $\mathrm{Ag}_{2} \mathrm{~S} / \mathrm{SiO}_{2} / 2-\mathrm{MPA}$ (рис. 2, $b$, кривая 3) наблюдается длинноволновый сдвиг максимума полосы люминесценции на $10 \mathrm{~nm}$ и пятикратное увеличение QY люминесценции. Причинами столь большого увеличения QY могут быть как пассивация поверхностных дефектов, так и более эффективная излучательная рекомбинация за счет локализации носителей заряда в ядре [33].

В спектрах люминесценции КТ $\mathrm{Ag}_{2} \mathrm{~S} / \mathrm{TGA}$ (рис. 2, $b$, кривая 4) наблюдается широкая полоса с максимумом при $960 \mathrm{~nm}$, полушириной $250 \mathrm{~nm}$ и низким QY порядка $0.01 \%$. Формирование оболочки $\mathrm{ZnS}$ (рис. 2, $b$, кривая 5) привело к увеличению QY в 2.6 раза и коротковолновому сдвигу максимума спектра люминесценции на $30 \mathrm{~nm}$. В образце с оболочкой $\mathrm{SiO}_{2}$ (рис. 2, $b$, кривая 6) отмечается рост QY в 35 раз и незначительный коротковолновой сдвиг максимума полосы люминесценции на $10 \mathrm{~nm}$. Учитывая низкий QY исходных КТ $\mathrm{Ag}_{2} \mathrm{~S}$, можно предположить, что при данном синтезе образуются КТ с большим количеством поверхностных дефектов. Повидимому, причиной является используемый $\mathrm{Na}_{2} \mathrm{~S}$ как прекурсор серы, который быстро отдаёт ионы серы во время синтеза. Пассивация поверхностных дефектов в результате формирования оболочки вместе с эффективной локализацией носителей заряда в ядре способствует росту QY.

\section{4. Кинетика затухания люминесценции и константы рекомбинации}

Наблюдаемое в спектрах фотолюминесценции изменение интенсивности и QY сопровождается изменени- ем кинетики затухания люминесценции (рис. 2, $c$, кривые 1-6). Кривые затухания люминесценции для всех образцов во временном диапазоне до $1000 \mathrm{~ns}$ неэкспоненциальны. Для определения среднего времени жизни люминесценции экспериментальные кривые аппроксимировали суммой трех экспонент:

$$
\begin{gathered}
I(t)=\sum_{i=1}^{3} a_{i} \exp \left[-t / \tau_{i}\right], \\
\langle\tau\rangle=\frac{\sum_{i=1}^{3} a_{i} \tau_{i}}{\sum_{i=1}^{3} a_{i}},
\end{gathered}
$$

где $a_{i}$ и $\tau_{i}$ - это амплитуда и время жизни $i$-й компоненты. Данные о среднем времени жизни люминесценции представлены в табл. 2. Их сопоставление с данными о времени жизни экситонной люминесценции, составляющем для $\mathrm{Ag}_{2} \mathrm{~S}$ QDs порядка $10 \mathrm{~ns}$ [42], свидетельствует в пользу рекомбинационного характера исследуемой ИК люминесценции, для которого по данным работ $[43,44]$ значение среднего времени жизни люминесценции составляет десятки и сотни наносекунд.

Принципиальной обнаруженной закономерностью является увеличение среднего времени жизни люминесценции с ростом ее QY и наоборот. Полученные данные позволяют вычислить константы рекомбинации КТ. Воспользуемся подходом, использованным нами ранее в работе [34]. В нём предполагалось, что электрон (в случае $\mathrm{Ag}_{2} \mathrm{~S}$ люминесценция возникает при рекомбинации локализованного электрона со свободной дыркой, и на центр люминесценции захватывается электрон) быстро захватывается центром люминесценции и не участвует в безызлучательной рекомбинации. Быстрый 
Таблица 2. Среднее время жизни люминесценции, QY люминесценции, константы излучательной и безызлучательной рекомбинации

\begin{tabular}{l|c|c|c|c}
\hline $\begin{array}{l}\text { Наименование } \\
\text { образца }\end{array}$ & $\langle\tau\rangle, \mathrm{ns}$ & $\mathrm{QY}, \%$ & $k_{r}, \mathrm{~s}^{-1}$ & $k_{n r}, \mathrm{~s}^{-1}$ \\
\hline $\mathrm{Ag}_{2} \mathrm{~S} / 2-\mathrm{MPA}$ & 58 & 1.6 & $2.76 \cdot 10^{5}$ & $1.7 \cdot 10^{7}$ \\
$\mathrm{Ag}_{2} \mathrm{~S} / \mathrm{ZnS} / 2-\mathrm{MPA}$ & 194 & 2.0 & $1.03 \cdot 10^{5}$ & $5.05 \cdot 10^{6}$ \\
$\mathrm{Ag}_{2} \mathrm{~S} / \mathrm{SiO}_{2} / 2-\mathrm{MPA}$ & 87.6 & 8.0 & $9.13 \cdot 10^{5}$ & $1.05 \cdot 10^{7}$ \\
$\mathrm{Ag}_{2} \mathrm{~S} / \mathrm{TGA}$ & 3.4 & 0.01 & $2.97 \cdot 10^{5}$ & $2.96 \cdot 10^{8}$ \\
$\mathrm{Ag}_{2} \mathrm{~S} / \mathrm{ZnS} / \mathrm{TGA}$ & 14.3 & 0.026 & $1.82 \cdot 10^{5}$ & $6.97 \cdot 10^{7}$ \\
$\mathrm{Ag}_{2} \mathrm{~S} / \mathrm{SiO}_{2} / \mathrm{TGA}$ & 18 & 0.35 & $1.95 \cdot 10^{6}$ & $5.45 \cdot 10^{7}$
\end{tabular}

захват электрона косвенно подтверждается отсутствием экситонной люминесценции. В таком случае будет потушен только центр люминесценции, и для связи QY, констант излучательной и безызлучательной рекомбинации можно воспользоваться выражениями для простой двухуровневой системы:

$$
\mathrm{QY}=\frac{k_{r}}{k_{r}+k_{n}}=k_{r}\langle\tau\rangle \quad \text { или } \quad k_{r}=\frac{\mathrm{QY}}{\langle\tau\rangle},
$$

где $k_{r}, k_{n r}$ - константы излучательной и безызлучательной рекомбинации, $\langle\tau\rangle-$ среднее время жизни люминесценции $\langle\tau\rangle=\frac{1}{k_{r}+k_{n r}}$. Отсюда константа безызлучательной рекомбинации

$$
k_{n r}=k_{r}\left(\frac{1-\mathrm{QY}}{\mathrm{QY}}\right) .
$$

Данные о константах рекомбинации также приведены в табл. 2

Для КТ $\mathrm{Ag}_{2} \mathrm{~S} / 2-\mathrm{MPA}$ измеренное среднее время жизни составило $58 \mathrm{~ns}$, значения констант излучательной и безызлучательной рекомбинации составили $2.76 \cdot 10^{5} \mathrm{~s}^{-1}$ и $1.7 \cdot 10^{7} \mathrm{~s}^{-1}$. Для КТ $\mathrm{Ag}_{2} \mathrm{~S} / \mathrm{TGA}$ среднее время жизни составило всего $3.4 \mathrm{~ns}$ при низком QY $0.01 \%$, что дало значения констант излучательной и безызлучательной рекомбинации $2.97 \cdot 10^{5} \mathrm{~s}^{-1}$ и $2.96 \cdot 10^{8} \mathrm{~s}^{-1}$. Примечательно, что значения констант излучательной рекомбинации практически совпали. Константа безызлучательной рекомбинации для КТ $\mathrm{Ag}_{2} \mathrm{~S} / \mathrm{TGA}$ значительно больше, что указывает на образование большого числа дефектов при синтезе. Формирование оболочки $\mathrm{ZnS}$ на KT $\mathrm{Ag}_{2} \mathrm{~S} / 2$-MPA сопровождалось ростом среднего времени жизни в 3.3 раза до $194 \mathrm{~ns}$. При этом и излучательная, и безызлучательная константы уменьшились относительно исходного образца в 2.6 и 3.4 раза до $1.03 \cdot 10^{5} \mathrm{~s}^{-1}$ и $5.05 \cdot 10^{6} \mathrm{~s}^{-1}$ соответственно. Уменьшение безызлучательной константы указывает на пассивацию дефектов оболочкой. Сходный результат наблюдается для КТ $\mathrm{Ag}_{2} \mathrm{~S} / \mathrm{ZnS} / \mathrm{TGA}$. Время жизни люминесценции увеличилось в 4.2 раза - с 3.4 до $14.3 \mathrm{~ns}$, при этом QY люминесценции увеличился в 2.6 раза. Константы излучательной и безызлучательной рекомбинации так же уменьшились: в 1.6 раза - до $1.82 \cdot 10^{5} \mathrm{~s}^{-1}$ и в 4.2 раза до $5.45 \cdot 10^{7} \mathrm{~s}^{-1}$ соответственно.

Формирование оболочек $\mathrm{SiO}_{2}$ в обоих случаях привело к увеличению излучательной и уменьшению безызлучательной констант рекомбинации при значительном увеличении QY люминесценции. Для КТ $\mathrm{Ag}_{2} \mathrm{~S} / 2-\mathrm{MPA}$ наблюдалось увеличение среднего времени жизни люминесценции до $87.6 \mathrm{~ns}$, константы излучательной рекомбинации - в 3.3 раза до $9.13 \cdot 10^{5} \mathrm{~s}^{-1}$ и и уменьшение константы безызлучательной рекомбинации - в 1.6 раза до $1.05 \cdot 10^{7} \mathrm{~s}^{-1}$. Схожий результат наблюдается и для КТ $\mathrm{Ag}_{2} \mathrm{~S} / \mathrm{TGA}$, где формирование оболочки $\mathrm{SiO}_{2}$ привело к увеличению QY люминесценции в 35 раз, среднего времени жизни в 5.2 раза до $18 \mathrm{~ns}$, увеличению константы излучательной рекомбинации в 6.5 раз до $1.95 \cdot 10^{6} \mathrm{~s}^{-1}$ и уменьшению безызлучательной в 5.5 раз до $5.45 \cdot 10^{7} \mathrm{~s}^{-1}$. Причинами данных явлений, вероятно, являются пассивация поверхностных дефектов и увеличение эффективности рекомбинации за счёт локализации носителей заряда в ядре ввиду большой разницы в ширине запрещенных зон КТ и $\mathrm{SiO}_{2}$ оболочки.

\section{5. Заключение}

В настоящей работе рассмотрены закономерности влияния оболочек I и II типов на рекомбинационную люминесценцию коллоидных КT Ag2S, покрытых молекулами 2-MPA и TGA. Показано, что оболочки обоих типов увеличили QY люминесценции КТ и уменьшили константу безызлучательной рекомбинации. Учитывая, что рекомбинационная люминесценция КТ $\mathrm{Ag}_{2} \mathrm{~S}$ имеет интерфейсную природу, сделано предположение, что причиной уменьшения эффективности безызлучательной рекомбинации является пассивация поверхностных дефектов КТ в результате формирования оболочки. Показано, что оболочка $\mathrm{ZnS}$ в обоих случаях приводит к снижению константы излучательной рекомбинации. На основе полученных данных сделано предположение о том, что причиной является взаимное расположение энергетических зон $\mathrm{Ag}_{2} \mathrm{~S}$ и $\mathrm{ZnS}$, обеспечивающее локализацию дырок в ядре и разделение носителей зарядов. $\mathrm{B}$ противоположность этому для оболочек $\mathrm{SiO}_{2}$ показано резкое увеличение эффективности излучательной рекомбинации, что обусловлено эффективной локализацией электрона и дырки в ядре.

\section{Благодарности}

Исследования ТЕМ осуществлены на просвечивающем микроскопе Libra 120 PLUS в центре коллективного пользования научным оборудованием Воронежского государственного университета.

\section{Финансирование работы}

Работа выполнена при поддержке грантом Российского научного фонда No 19-12-00266. 


\section{Конфликт интересов}

Авторы заявляют об отсутствии конфликта интересов.

\section{Список литературы}

[1] Frecker T., Bailey D., Arzeta-Ferrer X., McBride J., Rosenthal S.J. // ECS J. Solid State Sci. Technol. 2016. V. 5. P. R3019. doi 10.1149/2.0031601jss

[2] Petryayeva E., Russ Algar W., Medintz I.L. // Appl. Spec. 2013. V.67. P.215. doi 10.1366/12-06948

[3] Jin H., Gui R., Gong J., Huang W. // Biosens. Bioelectron. 2017. V. 92. P. 378. doi 10.1016/j.bios.2016.10.093

[4] Bera D., Qian L., Tseng T.-K., Holloway P.H. // Materials. 2010. V. 3. P. 2260. doi $10.3390 / \mathrm{ma} 3042260$

[5] Dios A.S., Díaz-García M.E. // Analytica Chimica Acta. 2010. V. 666. N 1-2. P. 1. doi 10.1016/j.aca.2010.03.038

[6] Ни M., Zhu T. // Nanoscale Res. Lett. 2015. V. 10. P. 469.

[7] Davis N.J.L.K., Allardice J.R., Xiao J., Karani A., Jellicoe T.C., Rao A., Greenham N.C. // Mater. Horiz. 2019. V. 6. P. 137. doi 10.1039/c8mh01122b

[8] Gui R., Jin H., Wang Z., Tan L. // Coord. Chem. Rev. 2015. V. 296. P. 91. doi 10.1016/j.ccr.2015.03.023

[9] Gui R., Wan A., Liu X., Yuanc W., Jin H. // Nanoscale. 2014. V. 6. P. 5467. doi $10.1039 / \mathrm{c} 4 \mathrm{nr} 00282 \mathrm{~b}$

[10] Gui R., Sun J., Liu D., Wang Y., Jin H. // Dalton Trans. 2014. V. 43. P. 16690. doi 10.1039/c4dt00699b

[11] Tang R., Xue J., Xu B., Shen D., Sudlow G.P., Achilefu S. // ACS Nano. 2015. V. 91. P. 220. doi 10.1021/nn5071183

[12] Sadovnikov S. I., Gusev A.I., Rempel A.A. // Superlattices and Microstructures. 2015. V. 83. P. 35. doi 10.1016/j.spmi.2015.03.024

[13] Ovchinnikov O.V., Grevtseva I.G., Smirnov M.S., Kondratenko T.S. // J. Lumin. 2019. V. 207. P. 626. doi 10.1016/j.jlumin.2018.12.019

[14] Смирнов М.С., Овчинников О.В., Гревцева И.Г., Звягин А.И., Перепелица А.С., Ганеев Р.А. // Опт. спектр. 2018. T. 124. № 5. C. 681; Smirnov M.S., Ovchinnikov O.V., Grevtseva I.G., Zvyagin A.I., Perepelitsa A.S., Ganeev R.A. // Opt. Spectrosc. 2018. V. 124. N 5. P. 681. doi 10.1134/S0030400X18050211

[15] Sun J., Yu W., Usman A., Isimjan T.T., DGobbo S., Alarousu E., Mohammed O.F. // J. Phys. Chem. Lett. 2014. V. 5. P. 659. doi $10.1021 /$ jz5000512

[16] Andreakou P., Brossard M., Li C., Bernechea M., Konstantatos G., Lagoudakis P.G. // J. Phys. Chem. C. 2013. V. 117. N 4. P. 1887. doi 10.1021/jp3054108

[17] Agrawal B., Maity P. // Rev.Adv. Mater. Sci. 2017. V. 49. N 2. P. 189.

[18] Semonin O.E., Luther J.M., Beard M.C. // Materials Today. 2012. V. 15. № 11. P. 508.

[19] Graham-Rowe D. // Nature Photonics. 2009. V. 3. P. 307. doi 10.1038/nphoton.2009.79

[20] Ovchinnikov O.V., Grevtseva I.G., Smirnov M.S., Kondratenko T.S., Perepelitsa A.S., Aslanov S.V., Khokhlov V.U., Tatyanina E.P., Matsukovich A.S. // Opt. Quant. Electron. 2020. V. 52. P. 198. doi $10.1007 / \mathrm{s} 11082-020-02314-8$

[21] Овчинников О.В., Смирнов М.С., Шапиро Б.И., Кондратенко Т.С., Перепелица А.С., Королев Н.В. // ФТП. 2015. Т. 49. № 3. C. 385; Ovchinnikov O.V., Smirnov M.S., Shatskikh T.S., Perepelitsa A.S., Korolev N.V.,
Shapiro B.I. // Semiconductors. 2015. V. 49. N 3. P. 373. doi 10.1134/S1063782615030173

[22] Uematsu T., Maenosono S., Yamaguchi U. // J. Phys. Chem. B. 2005. V. 109. P. 8613. doi $10.1021 / \mathrm{jp} 050328 \mathrm{k}$

[23] Jiang P., Zhu C., Zhu D., Zhang Z., Zhang G., Pang D. // Mater. Chem. C. 2015. V. 3. P. 964. doi $10.1039 / \mathrm{C} 4 \mathrm{TC} 02437 \mathrm{~K}$

[24] Karimipour M., Moradi N., Molaei M. // J. Lumin. 2017. V. 182. P. 91. doi 10.1016/j.jlumin.2016.09.063

[25] Li H., Xie F., Li W., Yang H., Rony Snyders R., Chen M., Li W. // Catal. Surv. Asia. 2018. V. 22. P. 156. doi 10.1007/s10563-018-9249-2

[26] Shen S., Zhang Y., Peng L., Du Y., Wang Q. // Angew. Chem. Int. Ed. 2011. V. 50. P. 7115. doi 10.1002/anie.201101084

[27] Jiang P., Wang R., Chen Z. // RSC Adv. 2015. V. 5. P. 56789. doi 10.1039/C5RA08008H

[28] Karimipour M., Izadian L., Molaei M. // J. Lumin. 2018. V. 33. N 1. P. 202. doi 10.1002/bio.3402

[29] He H., Xue S., Wu Z., Yu C., Yang K., Zhu L., Zhou W., Liu R. // J. Mat. Res. 2017. V. 31. N 17. P. 2598. doi $10.1557 /$ jmr.2016.284

[30] Karimipour M., Keshavarz A., Molaei M. // J. Lumin. 2018. V. 195. P. 339. doi 10.1016/j.jlumin.2017.11.044

[31] Васильев Р.Б., Дирин Д.И., Гаськов А.М. // Успехи химии. 2011. T. 80. № 12. C. 1190; Vasiliev R., Dirin D., Gaskov A. // Russian Chemical Reviews. 2011. V. 80. N 12. P. 1193. doi 10.1070/RC2011v080n12ABEH004240

[32] Wang L., Nonaka K., Okuhata T., Katayama T., Tamai N. // J. Phys. Chem. C. 2018. V. 122. N 22. P. 12038. doi $10.1021 /$ acs.jpcc.7b11684

[33] AbouElhamd A.R., Khaled A.A.-S., Hassan A. // Energies. 2019. V. 12. P. 1058. doi 10.3390/en 12061058

[34] Ovchinnikov O.V., Aslanov S.V., Smirnov M.S., Grevtseva I.G., Perepelitsa A.S. // RSC Adv. 2019. V. 9. P. 37312. doi 10.1039/C9RA07047H

[35] Reindl S., Penzkofer A., Gong S.-H., Landthaler M., Szeimies R. M., Abels C., Baumler W. // J. Photochem. Photobiol. A. 1997. V. 105. P. 65. doi 10.1016/S1010-6030(96)04584-4)

[36] Lakowicz J.R. Principles of Fluorescence Spectroscopy. Springer, 2006. $954 \mathrm{p}$.

[37] Lin S., Feng Y., Wen X., Zhang P., Woo S., Shrestha S., Conibeer G., Huang S. // J. Phys. Chem. 2015. V. 119. P. 867. doi 10.1021/jp511054g

[38] Kayanuma Y. // Phys. Rev. B: Condens. Matter Mater. Phys. 1988. V. 38. P. 9797. doi 10.1103/PhysRevB.38.9797

[39] Stevanovic V., Lany S., Ginley D.S., Tumas W., Zunger A. // Phys. Chem. Chem. Phys. 2014. V. 16. P. 3706. doi $10.1039 / \mathrm{c} 3 \mathrm{cp} 54589 \mathrm{j}$

[40] Guo Y., Lei H., Li B., Chen Z., Wen J., Yang G., Fang G. // RSC Adv. 2014. V. 6. P. 77701. doi 10.1039/c6ra19590c

[41] Fujimura N., Ohta A., Makihara K., Miyazaki S. // Jpn. J. Appl. Phys. 2016. V. 55. P. 08PC06. doi 10.7567/JJAP.55.08PC06

[42] Mir W.J., Swarnkar A., Sharma R., Katti A., Adarsh K.V., Nag A.J. // Phys. Chem. Lett. 2015. V. 6. P. 3915. doi 10.1021/acs.jpclett.5b01692

[43] Tan L., Wan A., Li H. // ACS Appl. Mater. and Int. 2014. V. 6. P. 18. doi 10.1021/am404534v

[44] Wang Y., Yan X.P. // Chemical Communications. 2013. V. 49. P. 3324. doi 10.1039/C3CC41141A 